Asmaa S AL-Douri

BDS, MSC, PhD( Assit Prof)

Sahar Gh A Al-kazaz

BSc, MSc (Assist Lect)
The Effect of Nigella Sativa Oil (Black Seed) on the Healing of Chemically Induced Oral Ulcer in Rabbit (Experimental Study)

\section{Department of Oral and Maxillofacial Surgery}

College of Dentistry, University of Mosul

$$
\begin{aligned}
& \text { الملاصة } \\
& \text { الهدف :التجربة الحالية نفذت لمحاولة أيجاد التأثير الموضعي لزيت حبة السوداء على شفاء التقرح الفموي.المواد والطرق: أجريت التجربة على عشرين أرنب وقسمو الى الى }
\end{aligned}
$$

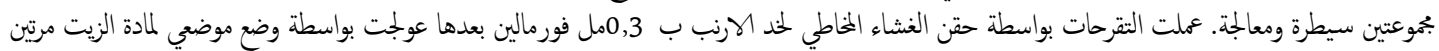

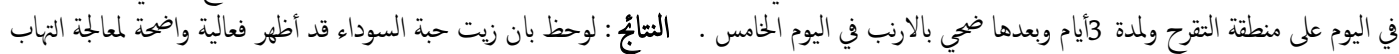

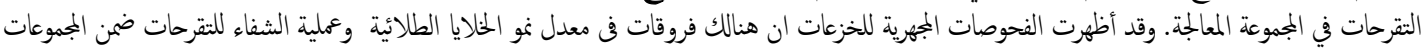

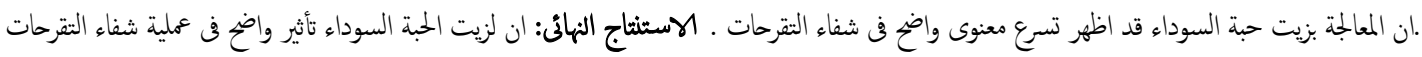

$$
\begin{aligned}
& \text { الفموية. }
\end{aligned}
$$

\title{
ABSTRACT
}

Aims: To find out the effect of topical Nigella Sativa oil on healing of chemically induced oral ulcer. Materials and Methods: Twelve rabbits were used and divided into control and treated groups, the ulcers were induced by injection of $0.3 \mathrm{ml} 1 \%$ formalin in rabbit cheek mucosa and were treated by daily application of black cumin (N.S) twice on the ulcer site for 3days then the animals were sacrificed 5days later. Results: Nigella Sativa (N.S) showed marked anti inflammatory activity on a chemically induced oral ulcer in experimental animals ,histological examination of biopsies from ulcers after three days of treatment revealed difference in the rate of epithelization and healing process of ulcers between the two groups, N.S treatment showed significant enhancement of healing of the ulcers. Conclusions: Nigella Sativa oil has an obvious effect on the rate of healing process of oral ulcer.

Key words: Nigella Sativa oil, oral ulcer

Al-Douri AS, Al-Kazaz SGhA. The Effect of Nigella Sativa Oil (Black Seed) on the Healing of Chemically Induced Oral Ulcer in Rabbit (Experimental Study). Al-Rafidain Dent J. 2010; 10(1):151-157.

Received: $15 / 10 / 2008$

Sent to Referees: $22 / 10 / 2008$

Accepted for Publication: 23/2/2009

\section{INTRODUCTION}

Recurrent Aphthous ulceration (R.A.U) or recurrent A. Stomatitisis the most common oral mucosal disease known to human beings, despite much clinical and research attention ${ }^{(1)} \mathrm{An}$ aphthous ulcer (canker sore) is a type of oral ulcer which presents as a painful open sore inside the mouth or upper throat, caused by a break in the mucous membrane. The condition is also known as aphthous stomatitis. The term aphtha means ulcer; it has been used for many years to describe areas of ulceration on mucous membranes. Aphthous stomatitis is a condition which is characterized by recurrent discrete areas of ulceration which are almost always painful. At least $10 \%$ of the population suffers from it, about $30-40 \%$ of patients with recurrent aphthae report a family history ${ }^{(2)}$.

Recurrent Aphthous Stomatitis is a Tcell mediated localized destruction of oral mucosa associated with an increased relative ratio of $\mathrm{CD} 8+\mathrm{T}$-cells to $\mathrm{CD} 4+\mathrm{T}$ cells. Minor ulcerations are the most common and least severe form of the disease. RAU develop in childhood and adolescence, and continue sporadically throughout life. RAU occur exclusively on non-keratinized, movable mucosa, such as buccal (cheeks) and lingual mucosa, the floor of the mouth, and the soft palate. It is characterized as a yellow-gray ulcer surrounded by an erythematous halo less than $10 \mathrm{~mm}$ in diameter. They tend to heal without scarring in 7-10 days. Major ulce- 
rations have the same appearance as minor ulcerations, but are greater than $10 \mathrm{~mm}$ in diameter and are extremely painful, they usually take more than a month to heal, and frequently leave a scar and these typically develop after puberty with frequent recurrences. They occur on moveable nonkeratinizing oral surfaces, but the ulcer borders may extend onto keratinized surfaces. The lesions heal with scarring and cause severe pain and discomfort. Herpetiform ulcerations are the most severe form, they occurs more frequently in females, and onset is often in adulthood. It is characterized by small, numerous, $1-3 \mathrm{~mm}$ lesions that form clusters. They typically heal in less than a month without scarring. Palliative treatment is almost always necessary. ${ }^{(3)}$

The exact cause of many aphthous ulcers is unknown. Factors that provoke them include Predisposing factors found may include the following:

1. Hematinic deficiency: Up to $20 \%$ of patients are deficient of iron, folic acid (folate), or vitamin B. ${ }^{(4)}$

2. Malabsorption in gastrointestinal disorders: About 3\% of patients experience these disorders, particularly celiac disease (gluten-sensitive enteropathy) but, occasionally, Crohn disease, pernicious anemia, and dermatitis herpetiformis. ${ }^{(5)}$

3. Cessation of smoking: This may precipitate or exacerbate RAS in some cases.

4. Stress: This underlies RAS in some cases; ulcers appear to exacerbate during school or university examination times.

5. Trauma: Biting of the mucosa and wearing of dental appliances may lead to some ulcers; RAS is uncommon on keratinized mucosae.

6. Endocrine factors in some women: RAS is clearly related to the progestogen level fall in the luteal phase of the menstrual cycle, and ulcers may then temporarily regress in pregnancy.

7. Allergies to food: Food allergies occasionally underlie RAS; the prevalence of atopy is high. ${ }^{(6)}$

8. Sodium lauryl sulphate (SLS): This is a detergent in some oral healthcare products that may produce oral ulceration. ${ }^{(7)}$

9. Immune deficiencies: Ulcers similar to RAS may be seen in patients with HIV and some other immune defects. ${ }^{(8)}$
10. Drugs, especially NSAIDs, alendronate, and nicorandil. These may produce lesions clinically similar to RAS. ${ }^{(9)}$

Mortality/Morbidity: Most patients with RAS are otherwise well. Race: RAS have been reported in all races. Sex: A slight female predominance exists. Age: RAS typically starts in childhood or adolescence. ${ }^{(10)}$

Histologic Findings: The histology is nonspecific. The ulcer is depressed well below the surface, and the inflammation extends deeply. The surface of the ulcer is covered by a fibrinous exudate infiltrated by polymorphs. Beneath is a layer of granulation tissue with dilated capillaries and edema. Deeper still is a repair reaction, with fibroblasts in the surrounding connective tissue laying down fibrous tissue. ${ }^{(11)}$

Nigella Sativa oil (black seed oil) is an annual flowering plant, native to southwest Asia. ${ }^{(12)}$ In Islam, it is regarded as one of the greatest forms of healing medicine available.The seeds of Nigella sativa (Ranunculaceae), commonly known as black seed or black cumin, are used in folk (herbal) medicine all over the world for the treatment and prevention of a number of diseases and conditions. The pharmacological actions of the crude extracts of the seeds (and some of its active constituents, e.g. volatile oil and thymoquinone) that have been reported include protection against nephrotoxicity and hepatotoxicity induced by either disease or chemicals. The seeds/oil has anti-inflammatory, analgesic, antipyretic, antimicrobial and antineoplastic activity. The seeds are characterized by a very low degree of toxicity. It would appear that the beneficial effects of the use of the seeds and thymoquinone might be related to their cytoprotective and antioxidant actions, and to their effect on some mediators of inflammation. ${ }^{(13,14)}$

\section{MATERIALS AND METHODS}

Twelve rabbits of eight males and four females weighed and average of 500-1000 gram were used in this study. Control group composed of six rabbits without treatment. Treated group by N.S oil application, composed of six rabbits. Ulcer formation: $0.3 \mathrm{ml}$ formalin $1 \%$ solution is injected in the rabbit check mucosa to induce a chemical ulcer. The rabbits were 
anesthetized by intra muscular injection of $0.15 \mathrm{ml} / \mathrm{kg} \mathrm{b}$. wt xylazine $-20 \mathrm{mg}$, in the left thigh before the formalin injection. After 24 hours following the injection, the animals were examined by measuring the site of the induced ulcer using calibrated probe and signs of inflammation were present, daily application of N.S oil on ulcer sites (twice daily) for 3 days, the animals sacrificed five day later and the tissue fixed in buffered formalin $10 \%$, then prepared for histopathological examination under light microscopic. microscopic examination of H\&E stained sections of 5 microns thickness from ulcers revealed difference in the rate of epithelization and healing process of ulcer between treated and control group.

\section{RESULTS}

The clinical manifestations:

Control group: Twenty four hours after formalin injection, the animals develop erythematous swelling about $1 \mathrm{~cm}$ in diameter; ulceration of the surface were seen in all animals. The animals looked irritated (suffering from pain during examination), this condition was observed for the following 3days In all animals throughout the period of the study, there was swelling, redness and pus discharge without signs of improvement till the end of study figures( 1) and (2).

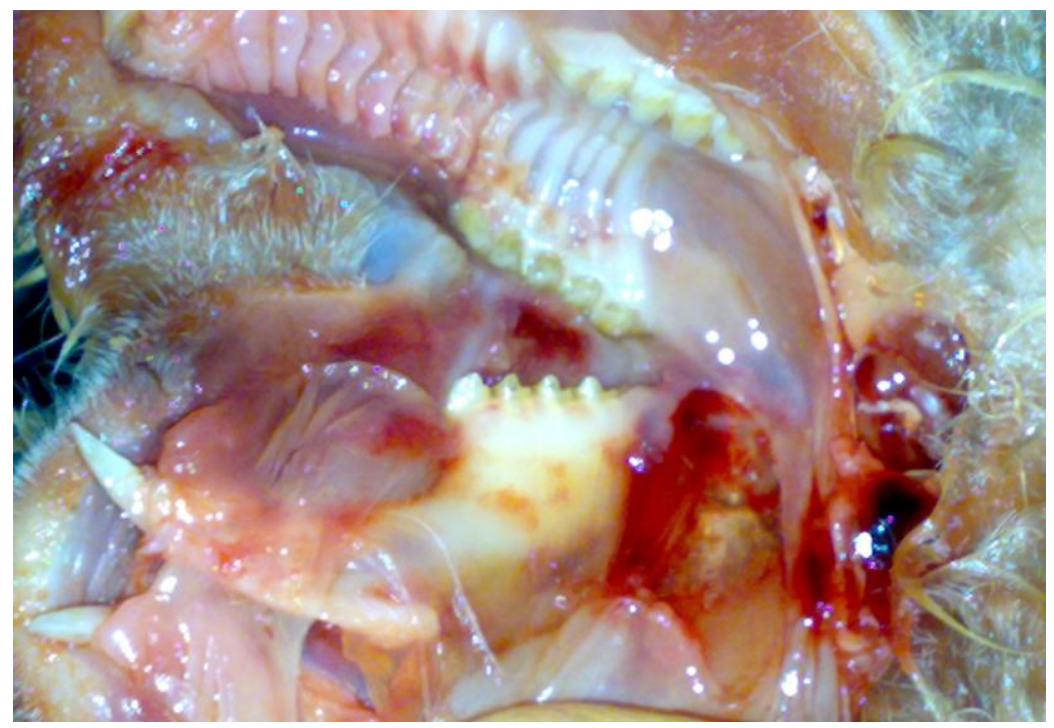

Figure (1): Photograph of rabbit cheek mucosa, induced chemical ulcer, one day after formalin injection.

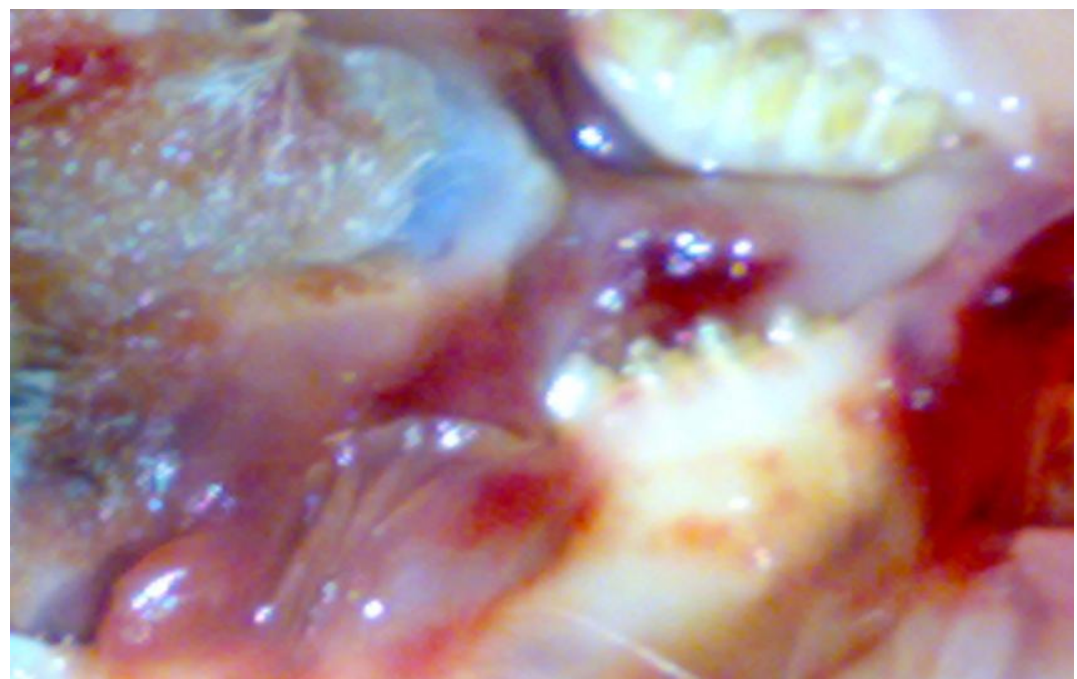

Figure (2): Photograph of rabbit cheek mucosa, induced chemical ulcer of control group, showing at scarifying day $\left(5^{\text {th }}\right.$ day $)$, unhealed ulcer. 
Treated group: One day after treatment the clinical picture was slightly improved and the clinical signs were decreased two days after treatment. Three days after treatment the ulceration has almost completely disappeared, figures( 3 ), The signs were decreasing significantly, The $\mathrm{p}$ value for the treatment group compared to control group was significant in ulcer size and healing, table (1).

\section{The histological features:}

In control group there was abscess formation and necrosis of connective tissue, suppuration with congestion and evidence of hemorrhage as seen in figures (4 )and( $5)$.

In treated group; three days after treatment, sporadic inflammatory cell infiltration, the connective tissue was nearly normal in appearance illustrated in figures( 6), and (7).

Table 1 : The $P$-value for treated with control group.

\begin{tabular}{|c|c|c|}
\hline & $P$-value & Significancy \\
\hline Ulcer size & 0.012 & Significant \\
\hline Healing & 0.002 & Significant \\
\hline
\end{tabular}

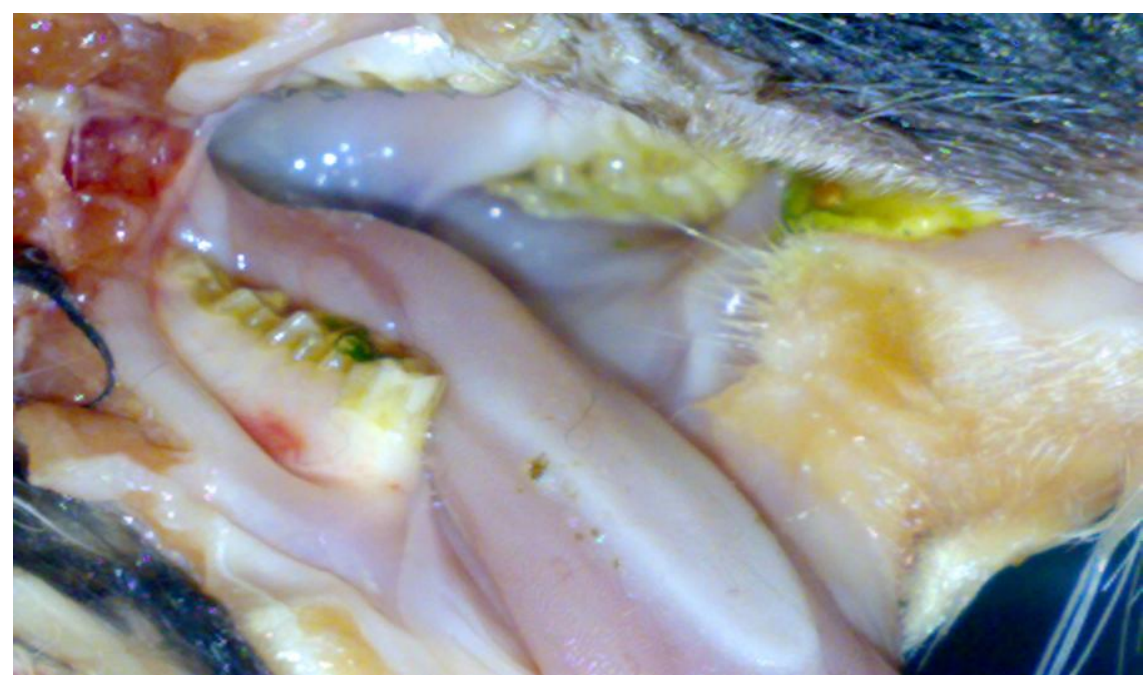

Figure (3): Photograph of rabbit cheek mucosa, treated by N.S. oil, showing at scarifying day $\left(5^{\text {th }}\right.$ day $)$, healed ulcer.

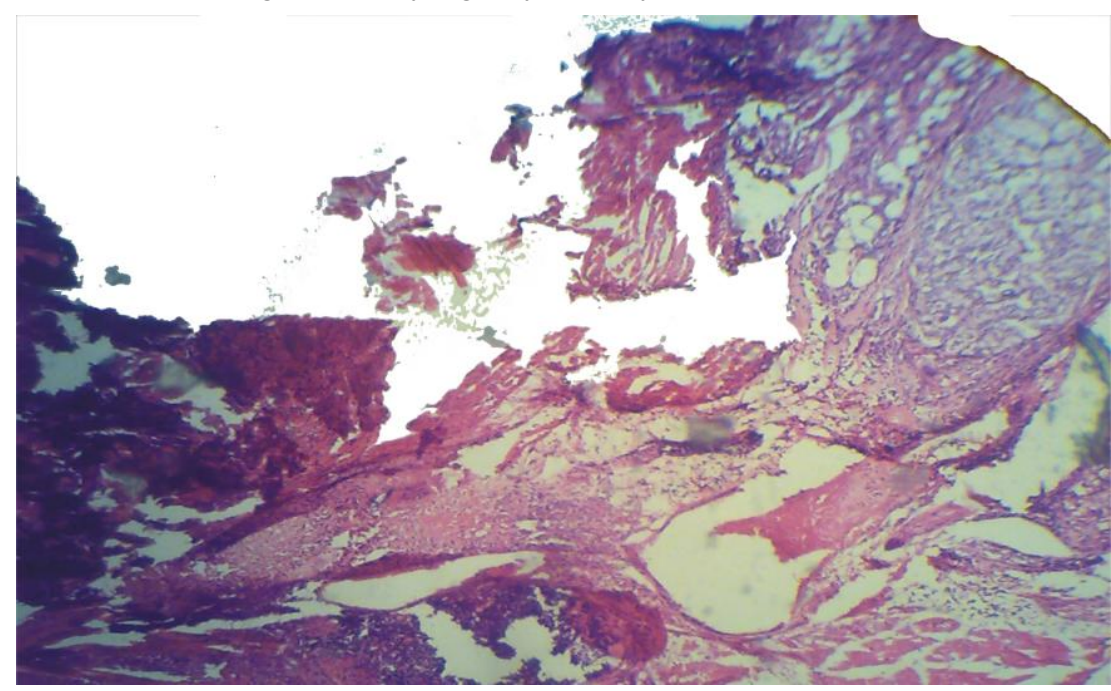

Figure (4): H\&E stained section of rabbit cheek mucosa, control group showing heavy collection of inflammatory cells, exudates with necrosis of the tissue, at $\left(5^{\text {th }}\right.$ day) .(X4) 


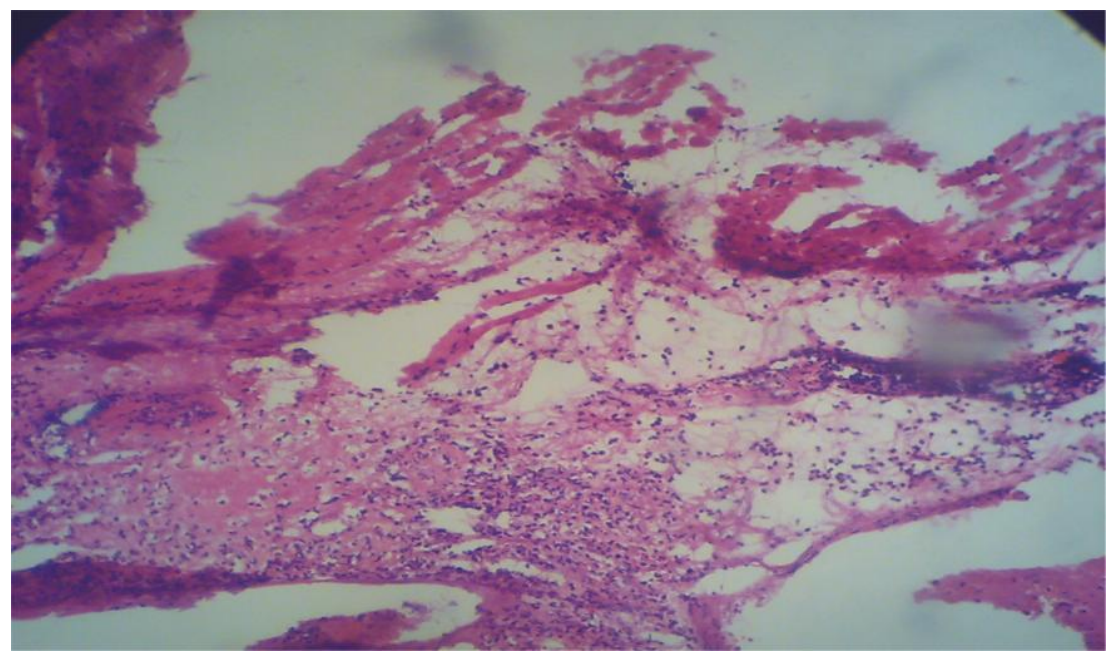

Figure (5): H\&E stained section of control group, notice inflammatory cells. (High power X10).

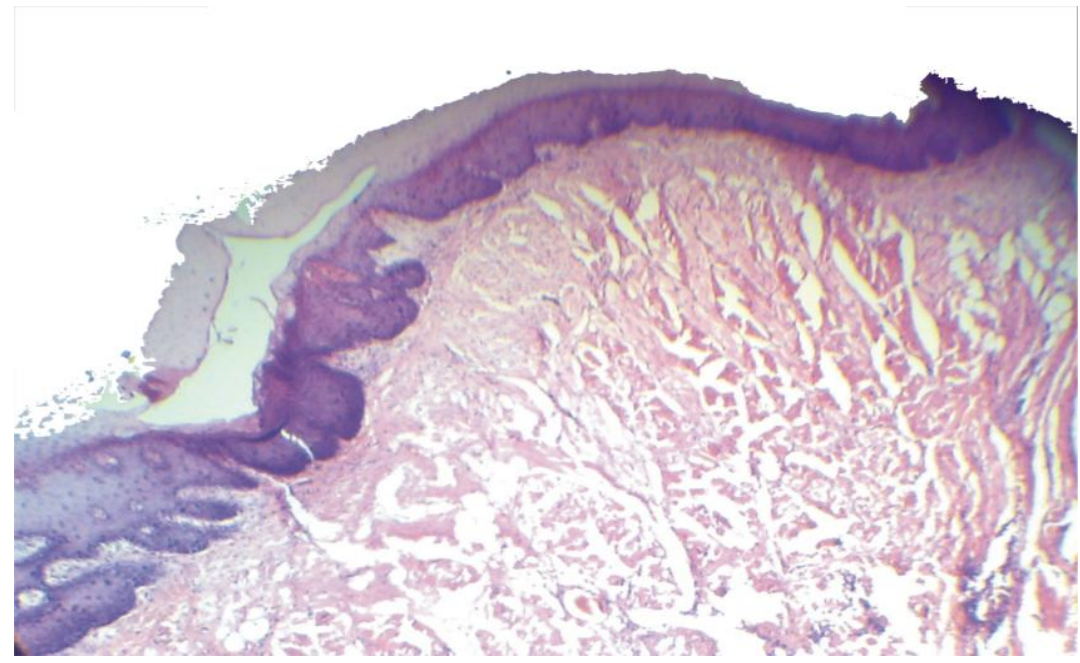

Figure (6): Rabbit cheek mucosa, after 3 days treatment with N.S. oil, section shows disappearance of inflammatory reaction, with complete epithelization. (X4)

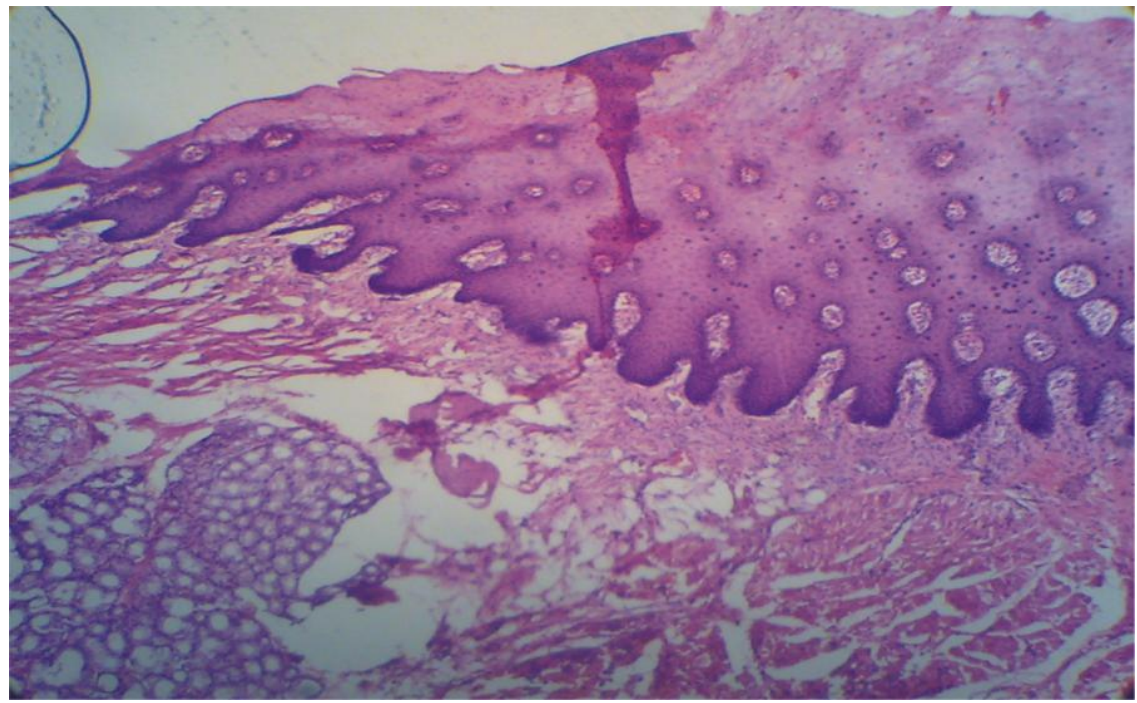

Figure (7): H\&E stained section, three days treatment with N.S. oil, showing no pathological change, healed lesion. (High power X10). 


\section{DISCUSSIONS}

In this study, the N.S. oil has therapeutic effect in the treatment of mucosal ulcer in agreement with the finding of Rajkapoor et al. ${ }^{(14)}$

N.S. oil accelerate the healing of ulcer because it may be effective against the growth of common pathogenic organisms (antibacterial, antifungal and antiviral) (that grow at the site of ulcers or wounds and retard the healing period),these finding in confirm with the studies of many researchers that N.S. oil was used to dress the ulcer wounds and there was no growth of microorganisms at the site of the wound $^{(15)}$, the predominate thymoquinone, flavonoids in N.S. oil, with other components of vitamins and minerals make this N.S. oil an excellent promoter of ulcer healing . In N.S. oil dressed ulcers, very early subsidence of acute inflammatory changes, better control of infection and quicker ulcer healing was observed, these finding confirm the studies of Kanter et al. (16)

The stimulation of poly_ morphonuclear leukocytes (PMNS) aggregation around the ulcer may promote fibrinogenesis and concurrent fibroblast proliferation by increasing the release of connective tissue activating proteins known to be produced by PMNS. Novak and Polson $(1989)^{(17)}$ stated that the using N.S. oil give a complete healing of the induced chemical ulcer with short time.

N.S. oil was probably the active constituents to absorb toxins from the mucous membrane and precipitates protein, so the pus and inflammatory exudates become absorbed by the N.S. oil thus protecting the underlying tissue and enhanced normal healing and the epitheliazation as honey ${ }^{(18)}$, and carob ${ }^{(19)}$. N.S. had also been reported to produce a marked inhibition on the release of leukotrienes which cause mucosal tissue injury and hypoxemia ${ }^{(20)}$. Therefore, it may alter the delicate balance between prostaglandin and leukotrienes in the gastric mucosa ${ }^{(16)}$, N.S. may have the same effect on oral mucosal ulcer.

No allergic mucosal reaction or toxins effects have been reported with N.S.oil usage.

\section{CONCLUSION}

N.S. oil treatment showed significant enhancement of healing of the oral ulcer.

\section{REFERENCES}

1. Jonathan A, Ship DM, Ann AM. Recurrent aphthous stomatitis. Oral Surg. Oral Med. Oral Pathol. Radiol. Endod. 1996; 81: 141-147.

2. Jurge S, Kuffer R, Scully C, Porter SR. "Mucosal disease series. Number VI. Recurrent aphthous stomatitis". Oral Dis. 2006; 12 (1): 1-21

3. Bruce AJ, Rogers RS. "Acute oral ulcers". Dermatol Clin. 2003; 21 (1): 1-15.

4. Wray D, Ferguson M, Hutcheon W, Dagg J. "Nutritional deficiencies in recurrent aphthae". J Oral Pathol. 1978; 7 (6): 418-23.

5. Bucci P, Carile F, Sangianantoni A, D'Angio F, Santarelli A, Lo Muzio L. "Oral aphthous ulcers and dental enamel defects in children with celiac disease.". Acta. Paediatrica. 2006; 95 (2): 203-7.

6. Lewkowicz N, Lewkowicz P, Banasik M, Kurnatowska A, Tchorzewski H. "Predominance of Type 1 cytokines and decreased number of CD4(+)CD25(+high) $\mathrm{T}$ regulatory cells in peripheral blood of patients with recurrent aphthous ulcerations.". Immunol. Lett. 2005; 99 (1): 57 62.

7. Herlofson B, Barkvoll P. "Sodium lauryl sulfate and recurrent aphthous ulcers. A preliminary study. Acta. Odontol. Scand. 1994; 52 (5): 257-9..

8. Ship JA, Chavez EM, Doerr PA. Recurrent aphthous stomatitis. Quintessence Int. 2000; 31(2):95-112.

9. Scully C. Clinical practice. Aphthous ulceration. N. Engl. J. Med. 2006; 355(2):165-72.

10. Eisen D, Lynch DP. Selecting topical and systemic agents for recurrent aphthous stomatitis. Cutis. 2001; 68(3):201-6.

11. Kumar V, Cotran R, Robbins S. Basic Pathology. $7^{\text {th }}$ edition. W.Saunders Company. 2003;Pp. 57 - 58.

12. Korshom M., Moghney, A.A. and Mandour, A. Biochemical and parasitological evaluation of Nigella sativa against ruminant fluke (Paramphistomum) in sheep as compared with trematocide 
"Hapadex". Assiut. Vaternary Med. J. 1998; 39 (78): 238-244.

13. Ali B. H., Gerald B. Pharmacological and toxicological properties of Nigella sativa. Phytotherapy Research. 2003; 17 (4): P 299 - 305.

14. Rajkapoor B, Anadan R, Jayakar B. Antiulcer effect of Nigella sativa linn. Against ulcers in rats. Current Sci. 2002; 82(2): 177.

15. Akhtar MS, Javeed J. Efficacy of Nigella sativa linn. Seed against Moniezia infection in sheep. Ind. Veter. J. 1991; 68: $726-729$.

16. Kanter M, Demir H, Karakaya C. et al. Gastroprotective activity of Nigella sativa linn. oil and its constituted, thymoquinone against acute alcohol - induced gastric mucosal injury in rats. World $J$. Gastroenterol.2005; 11(42): 6664.

17. Novak MJ, Polson AM. Effect of levamisole on experimental periodontitis. $J$. Periodontol.1989; 93: 137 - 144.

18. Aldouri AS. The effect of the honey on the healing process of oral ulcer (experimental study).Iraqi Dent. J. 2003, 33:7.

19. Al-Taie TS. The effect of the carob on the healing process of recurrent Aphthus ulceration and Herpes simplex ulceration. A thesis, College of Dentistry, University of Baghdad, Iraq. 1998.

20. Mansour MA. Protective effects of thymoquinone and desferrioxamine against hepatotoxicity of carbon tetrachloride in mice. Life Sci. 2000; 66: 2583 2591. 